Concept Paper

\title{
Environmental Activation of Inner Space Components in Sustainable Interior Design
}

\author{
Magdalena Celadyn \\ Academy of Fine Arts in Krakow, Faculty of Interior Design, pl. Matejki 13, 31-157 Krakow, Poland; \\ mceladyn@asp.krakow.pl; Tel.: +48-667-899-959
}

Received: 21 May 2018; Accepted: 7 June 2018; Published: 11 June 2018

\begin{abstract}
Implementation of environmental responsibility issues into the interior design methodology considers many aspects of the design process, but analyzes them separately. These include building materials' and products' specifications based on the assessment of their parameters impact on the users of indoor environments, or resource management within an ecological efficiency context. This concept paper concentrates on the analysis of an environmental activation of inner space components, identified by the author as the holistic and systemic design model, which is to empower the foundation of a contemporary sustainable interior design model. The proposed design scheme is supposed to assure the environmental effectiveness of interiors and their structure, as well as complementing functional components. The contributions of interiors completed in accordance with this concept can refer to the enhancement of the performance of building mechanical systems and the improvement in the indoor environment quality parameters. They can be achieved with the appropriate environmental activation-oriented structural, technical, and material solutions, applied to the selected inner space components. The theoretical scheme presented should become the basis for further investigations and studies to establish the comprehensive methodology design framework assuring the integrative role of interior design in the creation of a sustainable near environment.
\end{abstract}

Keywords: environmentally responsible interior design; sustainable interior design; environmental activation of interior elements; indoor environment quality

\section{Introduction}

The environmental responsibility of the interior design profession has been explored by researchers, architecture critics, and academics since the 1990s [1-3]. The increasing recognition of environmentally-sustainable design [1,4-6] has imposed on designers the necessity for a comprehensive and informed approach toward the interior design process. The notion of environmental responsibility in interior design can be interpreted as comprising the issues of: (1) an object's ecological effectiveness, with regard to the minimization of its negative impact on the natural environment; (2) the economic consequences and implications of the building spaces' energy performance; and (3) complementing social system's considerations related to the inner space quality parameters and their influence on the occupants' psychological and physical comfort. The constant interconnectedness and interdependence of these three systems is a major factor affecting the stability of the human ecosystem model and should be the subject of continuous investigation of environmentally-responsible interior designers [1] when searching for the optimization of the functionality and quality of inner spaces [4].

Although the term 'green design' is interchangeably used with ecological, environmentally-respo nsible, or sustainable design [3,7], it applies to the micro-scale of the interior [1]. The interior is defined as part of the built environment being in direct mediation with the space occupants and constituting the nearest area for their activities. It directly influences their health and well-being, and stimulates their behavioral patterns [8], as created in accordance with the sustainability paradigm. The interior 
designers accomplishing this model are to respect the environmental implications, considering the multiple life cycle consequences of completed objects and, therefore, addressing global environmental problems [4]. The position of interior designers in the process of creation of the so-defined environmentally-oriented built environment is still not precisely and comprehensively determined [1] and appreciated. The possible range of their interventions into the indoor environment design is mainly based on the appropriate specifications of introduced building materials, products, equipment, and appliances. These are made with the introduction of the comparative and whole-life-material-cycle environmental preference method (EPM) [9], consideration of the embodied energy (EE) measures, inclusion of the life cycle assessment (LCA) method associating the energy and material flows with potential environmental impacts [10], and the multi-criteria environmental evaluation schemes into the interior design process. All are necessary for finding informed and knowledgeable interior design solutions.

All these issues reflect the environmentally-oriented consciousness of designers, although they are methodically verified under reliable research-based assessment schemes and, when being considered separately as subsequent sustainable goals to be achieved, lack a cohesive vision designed to establish and endorse their environment-oriented effectiveness.

The main objective of the presented study is to define the role and technical, as well as formal, opportunities for the specific interior components' environmental activation, which would enable the identification of sustainable goals for interiors and the successful achievement of sustainability requirements in architectural and interior design. The intention of the article is to propose an integrated interior design framework, enabling the development of a perspective demonstrating the range of the impact of interior design on the built environment performance, and the development of the holistic approach to interior design, as postulated for the built environments' design [11,12].

The author discusses the possible implications of the recommended comprehensive model on the improvement in the closed spaces' quality parameters through the coordinated design process. Subsequent sections identify the term of the interior design's environmental contextualization with regard to the accomplishment of the sustainability paradigm. They also provide an overview of possible effects obtained in the case of properly-conceived interior components which are oriented towards the ecological effectiveness in the creation of the sustainable built environment. The analysis of the effects of environmentally conscious interior design, presented in this article, is restricted to its substantial features which are the question of the means of improvement in the indoor environment quality parameters, achieved through the cohesive and evidence-based design of the interior [13], with emphasis on the role of interior components in the optimization of sustainability goals.

\section{A Model for Environmental Contextualization of Interior Components}

Design strategies that are supposed to be applied to the environmentally-conscious interior design involve meeting the demand for the sustainable use of environment and resources. This postulate combines demands for the reduction in material resources and the enhancement of the indoor environment quality, achieved due to the research findings derived from peer-reviewed journals or conducted observations and surveys, which constitute a basis for design solutions concerning the built environment [3].

The achievement of sustainable goals in interior design requires the redefinition of its position, and the provision of the contribution of interior design to shaping the quality of built environments. This has to be augmented by the advanced environmental contextualization $[14,15]$ consequently imposed on the interior and its components' creation (Figure 1). 


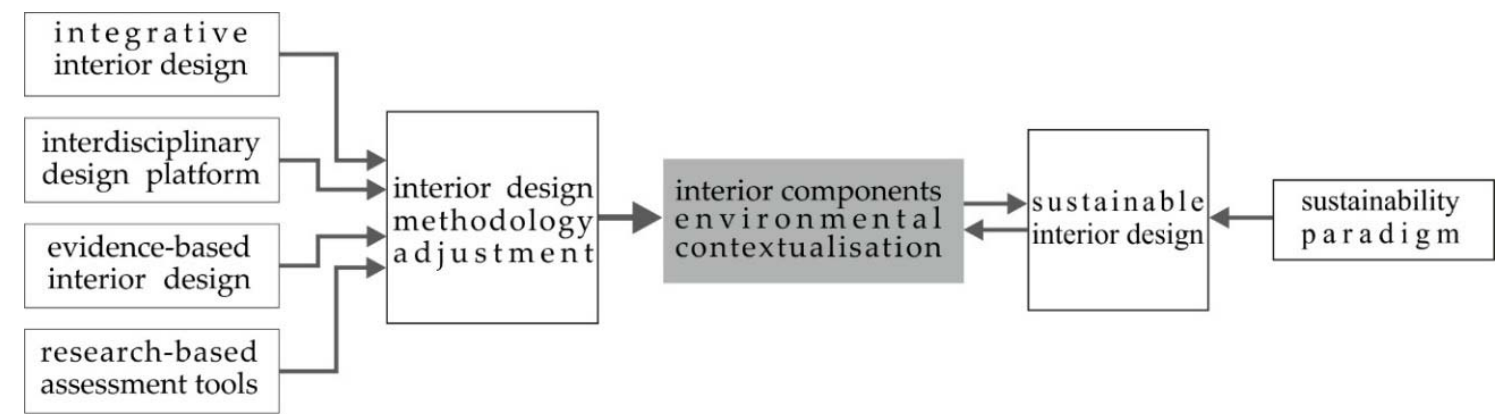

Figure 1. Interior components' multifaceted environmental contextualization as a function of the interior design methodology adjustment. Source: author's drawing.

The environmental context in the creation of internal spaces, by adding to this process a multidimensional perspective within which they can be analyzed and explored, requires the introduction of several adjustments concerning the conventionally-applied architecture design methodology. These corrections should be oriented on holistic thinking and interdisciplinary communication [1] marked with the inclusion of different specialists into the decision-making process; among them are interior designers, working as partners and co-learners [16] on the basis of integrative design teams. Intensive workshop sessions, as the interdisciplinary communication platform for professionals involved into the design process, enable the verification of proposals based on evidence provided by the participants in search of the optimization of buildings' performance. These eco-charrettes, focused on the design sustainability-compliance [6], allow the interior designers engaged in the multi-disciplinary integrated design process, to identify the area of their possible intervention in search for the healthy built environment and to contribute their knowledge to informing the design.

Applying research-based design tools, as the instruments assuring systemic and comprehensive pondering of the interior design postulates as detailed in the whole building certification system guidelines, may enable the interior designers to identify the sustainability goals to be achieved in their projects. Multi-criteria evaluation schemes based on the parametric assessment dedicated to the whole building, or its inner spaces' energy saving-, pro-ecological- and social-oriented solutions evaluation (e.g., Leadership in Energy and Environment Design Green Building Rating System for Interior Design and Construction LEED ID + C certification scheme established by the USGBC in 2004), have become a contemporary professional architectural design tool for defining and measuring the sustainability of green buildings [17]. It assists in the prevention of greenwashing effect [1]. The interior certification systems are considered by many researchers and practitioners as formal assessment schemes ensuring the rigorous approach leading to the achievement of sustainability features $[4,6]$. They are also the reliable and systemic verification tools for the compliance with the sustainability demands of indoor environment and are designed to define the quantitative and qualitative criteria for the main indoor environment evaluation categories (e.g., WELL Building Standard, a certification system conceived in 2014 and administrated by the International WELL Building Institute). They seem to be specifically recommended for interior design practitioners, enabling them a systematic approach to fundamental sustainability demands.

\section{A Model for Environmental Activation of Interior Components}

The effectiveness of environmental contextualization claimed by the author assigned to the designed inner space as an entity, and to its structural and complemented elements, relies on the simultaneous and equivalent consideration of several involved interior areas with regard to their impact on economic, ecological, and social systems. These design features, in terms of their role in the space structure, include the interior layout respecting the building orientation and climatic requirements, building materials specification based on the environmental preference methods, and 
the inner space multifunctional forming and supplementing components with emphasis on their technical and formal solutions. The interior components' design concept should be oriented toward their shaping considering an active response to the question of constant interaction of natural and man-made systems, with the provisions of its consequences as to the inner space quality endorsement and the building's performance.

Two aspects seem to mostly determine the components' environmentally-oriented features, and the effectiveness of the idea of environmental contextualization, as major sustainable interior design imperatives. These are the multi-functionality of interior components combined with the adaptability of inner spaces to accommodate different activities, along with the resources management framework. They might facilitate the fulfillment of environmental postulates in practice.

Elements of inner space, as indicated by researchers and academics for decades now, should not be created by designers in a traditional way, including functional, formal, and aesthetic contexts, but should be conceived by interior designers in a more complex [8] and environmentally-oriented context. This process of the creation of interior components should rely on their consideration as those conventionally formed with the sustainability features [3] (p. 267).

The typologies of components constituting the inner space, as proposed by critics and researchers $[5,18,19]$, usually identify the groups according to their basic and auxiliary functions to be fulfilled. The structural forming of indoor components, as proposed in the author's classification [5], comprise: external walls determined as enclosures separating the inner space from the natural environment actively responding to the changing climate conditions and usually accompanied by various technical devices or natural finishing on the inner side; partitions and inner space dividers of various dimensions and finishes; raised floors; and suspended ceilings. Supplementing or completing interior components include: furniture, furnishings, equipment, and fixtures assigned to a separate category [5], enabling the proper usage of spaces in accordance with the exigencies.

The methods of structural forming of internal elements' and their integration with the building components, should be the consequence of designers' considerations of the interconnectedness of both natural and man-made environments, as well as predictions of possible consequences of their mutual interrelationship. As there are both direct and indirect relations between interiors and the environment [8] (p. 49), they should be specified, analyzed with scientific means, and reflected in the adjusted integrated interior design methodology.

The interior components' design strategy should identify the measures undertaken that respond to the users' needs, and positively affect their health and comfort, as well as minimize the objects' environmental load through the reduction in energy consumption by building systems. The strategies enabling the fulfillment of these, should combine the rational management of material resources, functional efficiency and formal diversity of components, their active inclusion into the overall integrated and indoor environment high-quality as supplementary means, and energy concepts.

\section{Environmental Activation of Components}

The presented model of multi-functionality of inner space components to be explored in the sustainable interior design framework, can be developed in order to identify its leading role in the consequent and comprehensive multi-faceted environmental activation of interior components. This design concept for complex components activation can be regarded as a valuable interior designers' contribution to the comprehensive accomplishment of sustainability imperatives.

A successful implementation of this model based on the comprehensive and environmentallyconscious interior design, and complying with the sustainability paradigm, requires designers to take into account the results of scientific studies in the field of technical disciplines including building physics, and climate engineering. The model can enable the integration of closed spaces in the built and natural environments obtained through: (1) endorsement of building systems as a substantial factor in the optimization of building's performance and related savings in energy consumption; (2) resource conservation as the result of rational management of building materials and products; 
and (3) improvement in indoor environment quality parameters (Figure 2). The latter aspect of the suggested design model, discussed in further sections, concentrates on the presentation of the components' creation methods that are introduced into interior design as passive modes may influence and positively stimulate the interior's quality parameters.

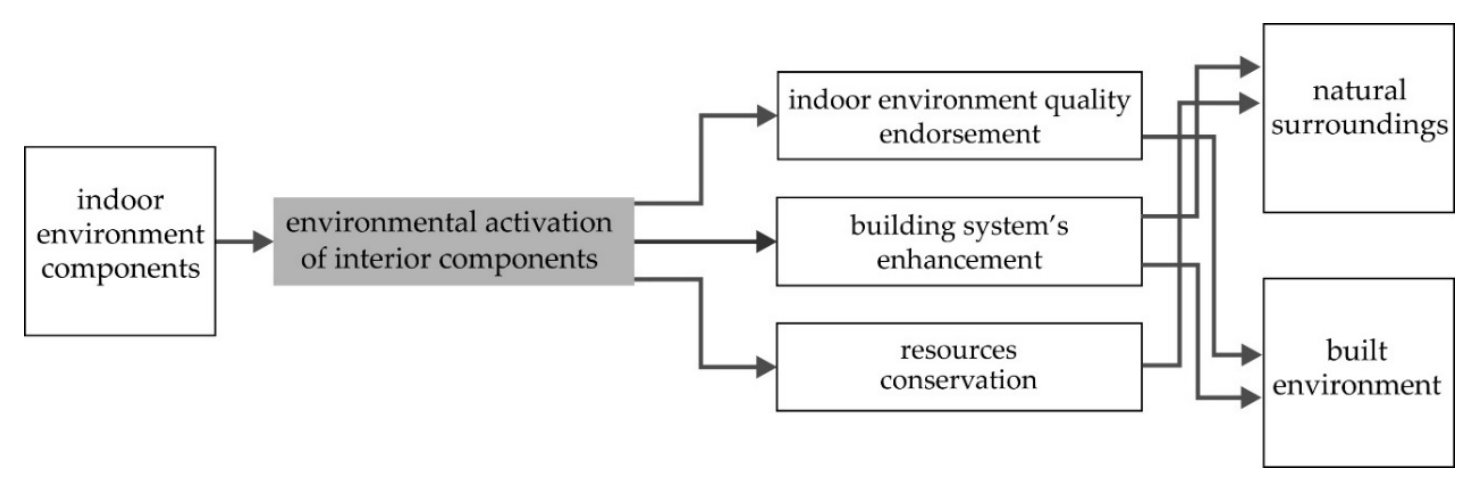

Figure 2. Design concept for environmental activation of interior components Source: author's drawing.

The improvement in lowering of the environmental impact of buildings on natural surroundings and inner spaces depends on the application of adequate technological and technical measures, as well as on the introduction of supportive passive methods. The latter may become a valuable contribution to the transition of interior design toward the accomplishment of sustainability paradigm, where the ecological, economic, and societal areas of human activities, are to remain in balance. The indicated requirements, being essential for the execution of sustainability issues in architectural design, can be met through the complex activation of inner space elements focused on the environmental responsibility.

Proposals for the definition of environmental activation of interior elements [14,15] are formulated as specific means of stimulation of these components to their action, performed and based on their' comprehensive and multi-criteria evaluation. This design method should play a substantial role in the interior decision-making process, for its multidimensional perspectives, identifying the functional, spatial, and temporal contexts. The main purpose of the environmental activation of interior elements, proposed in this paper, is to reduce the dependency of indoor environment quality on mechanical building systems, as well as to enhance the systems' performance. The recommended components' activation can be achieved by the properly analyzed setting of interior elements in inner spaces according to the users' individual requirements and organizational demands, by the elements' formal and structural forming, as well as their purposeful functional and formal integration with the main building structural components or building services.

The main objectives, which may be assigned to the activation concept, remain in accordance with a triple bottom line, which addresses the designers' responsibility in meeting the demands for the sustainability of economic, ecologic, and societal aspects of architectural design. These aims include the envisaged structurally, formally, and functionally combined solutions that should be considered as supportive building systems supplementing the passive means enabling:

- Enhancement of heating, ventilation, air conditioning (HVAC), and building lighting systems' effectiveness, assuring the increase in building performance and the decrease in energy and water consumption, as well as the reduction in operational costs;

- Reduction in the emission of toxic substances released in the production of building materials, and in the course of maintenance and conservation of buildings; and

- Optimization of the indoor environment quality (IEQ) parameters, related to the inner air characteristics, daylighting control, and acoustic conditions, in relation to the occupants' health and well-being. 
The analysis of the selected parameters, presented in the following sections, indicates the possibilities of innovative spatial and technical methods to positively stimulate their optimization. The daylight transmission and its redistribution in interiors' regulation of solar thermal energy gains preventing the spaces from overheating, combine the demand for reduction in material resources with the enhancement of indoor environment quality through the applied structural solutions.

\section{Components' Activation for the Optimization of Indoor Environment Quality}

The complexity of indoor environment quality issues warrants the integrated approach to the design of buildings [20] (p. 430), which are functional-spatial-formal entities. This relates also to their inner spaces and, specifically, to these conceived in the course of refurbishments or adaptation of existing objects. The closer analysis of this problem being substantial for the interior evaluation proves, that there are many considerations within the Indoor Environment Quality category for the work of an interior designer [3] (p. 261) which should be identified while carrying out an environmentally-responsible design. Interior designers, along with other professionals involved in the design process, may contribute to the expected properties of the main components of integrated Indoor Environment Quality design [21]. These features combine the inner air quality with thermal, lighting, daylighting, and acoustic parameters, providing users with the health environment [22] having an impact on the occupants' health, physical and psychological comfort, well-being and productivity [1].

These objectives can be realized by interior designers with the applied different measures based on the determined sustainable goals, concerning the cautious selection of building materials, and the innovative and comprehensive approach to the formation of inner structural elements oriented toward their functional integration with the enhanced building components and systems (e.g., inner walls designed as thermal masses and means of reduction in the consumption of heating energy).

\subsection{Indoor Air Quality}

The indoor environmental and air quality is strictly health-related [23] (p. 242) and, thus, its significance should be recognized by interior designers while preparing the specifications of products and building materials to be introduced into an inner space, as the occupants' exposition to the pollutants contained in products or furnishings may cause several diseases (e.g., cardiovascular and respiratory diseases, multiple chemical sensitivity (MCS)). The selection procedures should be based on the credible information provided by independent institutions in the result of research-based measurement and certification processes concerning the occupants' health-affecting attributes. This would enable the provision of designers with the knowledge on building biology [10], which reveals the interrelationship between humans and their living environment.

The designers' ability to assessing impacts ( ... ) leads to managing the risks [23] (p. 247) and, thus, to verifying of the consequences of their presence and effects on interiors features. Prior to the final decisions regarding the selection of constituting component products, the designers should provide the verification of possible influences of their introduction on the users' health, well-being, and comfort. The carefully selected building construction materials, structural components' solutions, as well as finishes can improve the indoor air quality. This refers to the following concerns:

- Regulation of the amount of pollutants in closed spaces and supported air purification;

- Reduction in solar heat gains and the enhancement of the monitoring of inner temperature, achieved by the individual users' control on thermal conditions and the way of spaces usage (e.g., presence of inner solar protection equipment manually adjustable);

- Reduction in daily fluctuations of inner air temperature by the free cooling effect (e.g., introduction of unfinished solid inner walls as passive thermal stores for the heating or cooling purposes and being exposed to solar heat $[4,24]$, suspended ceilings, inner side finishes of external walls or space forming components, and partitions filled with integrated phase change materials PCM); 
- Regulation of the radiant temperature and the usage of solid internal walls' thermal capacities with different finishes (e.g., porous surfaces of selected materials easy in maintenance, and increasing the heat absorption; removable wall finishing devices or hangings responding to seasonal climate changes and enabling the solid external walls to act as thermal masses in winter; and dark finishes of components situated in close proximity to glazed envelopes as thermal store and light finishes reflecting the heat [22]);

- Control of the relative humidity level of inner air (e.g., the supply of an adequate amount of water for growing plants and impeding the formation of mold in poorly-ventilated areas, 'bioclimatic' openwork inner walls made with materials of high permeability, components, or wall covering made with wood fiber panes).

These exemplary passive design methods should be recommended as environmentally-respons ible complementing means of maintaining the high-quality indoor air with the related reduction in the number of technologically-advanced and energy-consuming heating, ventilating, and air conditioning systems. Living walls, recommended for their air purifying- and conditioning potential, and vastly implemented in interiors, can become the essential passive means of maintaining good air quality, through the stabilization of the ambient temperature and indoor humidity level. The consequent installation of space dividers in the form of active green walls can contribute to the decrease in inner temperature, and play a complex role of airborne chemical filters, carbon dioxide absorbers, and the source of oxygen released during the daytime into the inner space. The indoor air quality can be further enhanced by the inclusion of living moss walls playing the role of internal buffers and helping in the removal of concentrated volatile organic compounds (VOC) and other chemical pollutants from the air and, thus, allowing the reduction in demanded ventilation rates. Plants broadly introduced into closed spaces assure for the users a connection to nature and affect their well-being, responding to the demand for the inclusion of the biophilic concept into the interior design model.

The 'bioclimatic' openwork inner walls and space dividers, made with gypsum, light concrete or ceramic tiles, may be seen as another valuable solution, which contributes to the thermal microclimate conditions and inner air relative humidity. These climate-stimulating structures in modernized and adapted buildings can be completed with building materials recovered and reused in new spatial contexts. Due to their abilities to exert a positive impact on the indoor environmental quality, they are examples of innovative techniques allowing the accomplishment of sustainability principles in interior design, through the concept respecting equally valuable design strategies.

\subsection{Daylighting}

The lighting scheme developed for interiors should include a vast amount of daylighting, since the use of natural light within the building and its interior is not only fundamental for the reduction in energy demand [5] but also for the minimization of the negative influence of seasonal affective disorder (SAD) which is a result of deficiency of daylight. Its abundance usually positively affects occupants' health and well-being with respect to the circadian stimulation and its positive influence on physical activity and perceptual effectiveness [25].

Apart from the technical devices assuring the users' individual control of the intensity of light at workplaces, the daylight-level and occupancy sensors or dimming devices keeping the electric energy demands on a reasonable level, there are many other possible solutions. The effective use of daylight can be a valuable contribution of interior designers frequently enhanced by consultations with lighting engineers. They may advance the occupants' well-being, ensuring their increased productivity and satisfaction.

These are supposed to ensure good daylighting levels on the floorplates and to provide a good amount of daylight in accordance with the enforced regulations, codes and standards. They have to be appropriate for space purposes, their functional requirements, and should enable the achievement of a high-quality visual environment. The main positive effects of designers' intervention into the methods of components' introduction with regard to the optimization of daylighting combine: 
- Minimization of the negative glare effect by the introduction of some functional components (e.g., manually controlled internal solar control blinds, louvers, supplementing devices eventually mounted externally, screens modulating the brightness of glazed surfaces, other components in the proximity of openings with highly reflective finishes);

- Minimization of the solar thermal heat gain (e.g., blinds, manually-controlled curtains);

- Ambient daylighting in fully-glazed spaces obtained with the structures suspended from the glazed roof support, translucent perforated fabrics [6], or framing structures made with lightweight bright finished materials mounted to the glazed envelope;

- Maximization of the quantity of incoming daylight by its reflection (e.g., window reveals finished with light-colored surfaces or reflective materials, like safety glass or metal sheets, reflective surfaces of internal components adjacent to openings [3], and enclosures separating spaces situated in a distance from glazed walls with their upper parts made with transparent or translucent panels);

- Reduction in the distracting contrast on the surfaces of working area caused by direct sunlight (e.g., fabrics mounted to the ceiling next to windows [6];

- Penetration of distracting daylight (e.g., introduction of clerestory windows with the complementing reflective finishing materials of sloped ceilings to optimize their performance $[1,3]$ );

- Redirection and transmission of daylight, as well as an increase in the illuminance of daylighting in the overall lighting supply (e.g., technical devices like reflective optical light tubes providing under-lit spaces with the demanded daylighting quantity, translucent inner light shelves integrated with the structure of the building's south side glazed envelope [1,8,24], or adjustable reflective panels suspended under the ceiling and anidolic integrated ceilings (AIC) $[24,26]) ;$ and

- Diffusion of daylight (e.g., wall cladding with reflective materials supplementing the semi-translucent diffusing panes suspended from the glazed roofs to obtain an effective daylight distribution [27]).

The methods commonly introduced into inner spaces which enable the control of the amount of daylight through the use of reflected light, combine the installation of blinds, curtains, louvers configured depending on the window orientation, or more technically-advanced means including opaque and translucent inner light shelves provided with reflective finishes of suspended ceilings. The additional structures like passive-daylight devices introduced by designers with respect to the existing interior layout, building orientation, and the volume of the glazing of envelopes (e.g., translucent polymer mobile optic diffusors suspended from the skylight and integrated with passive solar optic systems PSO), may effectively participate in the redirection of the daylight and its transmission into the parts situated at a distance from the glazed external walls [28]. Other implemented components made with glass fiber reinforced gypsum and painted white may enable the control of the amount of incoming daylight and the reduction of the light contrast, or a negative glare effect inside. The above-mentioned possible effects of the installation of internal components as passive-daylight means, define the range of the interior designers' formal contribution to the daylighting quality through the supportive, innovative and complex design approach, as well as by the environmental implications of assigned components' activation. The daylighting concept, for its effectiveness, should be conceived in accordance with the site conditions and activity-related illuminance requirements, measured and verified with computer simulations and integrated with the artificial lighting concept from the pre-design planning phase [3].

\subsection{Acoustic Conditions}

The rising demands among users for the controlled noise levels and the improvement in acoustical conditions of interiors, as well as the postulates of necessary acoustic privacy, are other interior design issues that have to be carefully considered by the environmentally-conscious designer. As the surveys conducted on the contribution of different factors to the distraction of workplaces confirm [6,29], noise 
remains the one most complained about. The acoustical comfort is one of the substantial features in the occupants' assessment of interior quality, influencing their health and wellbeing. On the other hand, the internal acoustic quality still neither has been recognized by designers as a primary issue in sustainable design [22], nor as a substantial assessment criterion of the indoor environment quality. Interior designers can carry out a balanced acoustical design of inner spaces and obtain a 'non-intrusive' speech privacy level [6,29], including the elimination of uncontrolled transmitting of distractive internal noises, absorbing sound or its masking. The efficiency of these and other applied solutions is assured by the improved space planning, through the selection of proper building materials and adequate formal and structural characteristics of internal components.

The design methods and techniques directed toward the improvement in acoustical comfort consist of:

- Reduction of the internal noise transmission (e.g., a functionally-resolved interior layout and spatial zoning, ceiling height enclosures complemented with transparent upper panes to enable light transmission, broad introduction of the sound proofing building materials constituting the layers of enclosures, ceiling finishes, or functional interior components); and

- Absorption of sound (e.g., acoustic absorber panels mounted directly to the ceiling, parallel to the glazed walls, and complemented with a finishing layer adjusted to the interior's spatial and formal concept [24]).

The accomplishment of good acoustic conditions, through the introduction of sound-absorbing building materials, may provide the interior design with substantial quality parameters, as well as to enhance the space unique formal and stylistic values. The sound-absorbing finishing layer of the composite partition wall made with demolished parts reclaimed from building bricks or ceramic tiles, and other reused materials, can separate intensively-used circulation areas from adjacent spaces. The exposed rough texture of the cut hollow bricks forming the inner wall layer, being a sound-dissipating and sound diffusing multi-faceted space divider, may be seen as an innovative means of control of the sound level, and the reduction in the reverberation time.

In addition, the building material of the finishing layer, massively incorporated as a sound absorber, participates in the process of modification of the level of inner air relative humidity, being one of the substantial considerations related to comfortable inner thermal conditions. Therefore, the choice of reclaimed building materials, made on the basis of an analysis of their physical and chemical parameters, enables the fulfillment of yet another sustainable design demand, regarding the optimization of indoor environment parameters and interior microclimate characteristics, as essential for the users' comfort. The introduction of building materials reclaimed on site and implemented into the objects' structure, as presented in the example of the possible installation of interior components, allows to achieve compliance with the requirement for the reduction in the amount of demolition wastes [16], as well as the effective waste resources' management.

\section{Conclusions}

This concept paper provides a proposal regarding the modification of interiors and their structure, as well as complementing the component design methodology enabling the compliance with the environmental sustainability paradigm. It demonstrates the multi-dimensional environmental approach in the creation of closed spaces as the basic concept for a sustainable interior design process.

The environmental activation of interior components, as the substantial element of the design method, results in multi-faceted benefits addressing the optimization of buildings and their indoor environment performance, reduction of their negative impact on the natural environment, and the establishing of real interconnectedness between manmade and natural environments.

The benefits of components' environmental activation, as an interior design imperative enabling the consideration of sustainability issues and the achievement of sustainable goals, in terms of the optimization of building materials and product consumption include: 
- Efficient management of interior components related to their multi-functionality;

- Resource management optimization due to the components' adaptability and applied structural and technical solutions; and

- Reclaiming of dismantled or removed components and their parts from refurbished spaces and their implementation into new structures as a design imperative to be considered within the environmentally-responsible design process.

The social benefits of the applied design method oriented on active response of components to their environmental interaction combine:

- Broad inclusion of stakeholders, including professionals of different specialties, owners, and end-users into the decision-making process;

- Responsible usage of the indoor environment treated as a scenery for the accommodation of different human activities, as well as a complex building product requiring rationality in its use affecting its performance;

- Increase in the environmental consciousness of the interiors' occupants through the understanding of interior component roles in shaping the quality of the indoor environment and their impact on natural surroundings; and

- Establishing a developed knowledge-based identity of occupants with their inner spaces in the process of experienced results of the environments' interconnectedness.

The components' environmental activation, as presented in the analysis, affects the performance of spaces within the following aspects:

- Enhancement of the building's artificial light system achieved with the optimization of daylight management through the implementation of multi-functional inner devices integrated with building components;

- Enhancement of ventilation systems through the properly executed space layout and space dividers' configuration; and

- Endorsement of heating/cooling, as well as air conditioning systems, with the assignment of additional functions to the components.

The qualitative assessment of the above-mentioned positive results derived from the enclosure of environmental activation concept into the interior design methodology indicate that this innovative cohesive approach toward the indoor environment and its components' creation may significantly affect the position of interior design discipline in the integrative sustainable design process. The examples of a range of structural and formal interventions by interior designers undertaken toward the effective compliance with the sustainability requirements presented above, prove that the concept of interior components' environmental activation, preceded by their multi-functionality model and multi-faceted environmental contextualization, can become a fundamental design method for the planning of inner spaces and the forming of components. This may assure the achievement of sustainable goals in the creation of interiors. The assignment of the essential meaning to the interior components' environmental contextualization in the interior design process, may become crucial in a search for synergy in sustainable interior and architectural design, as well as mechanical systems' designs.

The increasing recognition of environmentally-sustainable interior design [1,12] encourages designers to modify their design methodology in order to comply with the sustainability paradigm. The systemic problem solving applied to interior design, enabling the transition from degenerative architectural design through the transitional phase of sustainable design, assures the achievement of coexistence of natural and man-made environments. This can lead to a model actively supporting the idea of regenerative [30] architectural and interior design.

Conflicts of Interest: The author declares no conflict of interest. 


\section{References}

1. Jones, L. Environmentally Responsible Design: Green and Sustainable Design for Interior Designers; John Wiley \& Sons Inc.: Hoboken, NJ, USA, 2008; ISBN 978-0-471-76131-0.

2. Pilatowicz, G. Sustainability in Interior Design. Sustainability 2015, 8, 101-104. [CrossRef]

3. Winchip, S.M. Sustainable Design for Interior Environments, 2nd ed.; Fairchild Books: New York, NY, USA, 2011.

4. Moxon, S. Sustainability in Interior Design; Laurence King Publishing: London, UK, 2012.

5. Raymond, S.; Cunliffe, R. Tomorrow's Office. Creating Effective and Human Interiors; E \& FN Spon: London, UK; Taylor \& Francis Group: New York, NY, USA, 2000.

6. Bonda, P.; Sosnowchik, K. Sustainable Commercial Interiors, 2nd ed.; John Wiley \& Sons: Hoboken, NJ, USA, 2014.

7. Hayles, C.S. Environmentally sustainable interior design: A snapshot of current supply of and demand for green, sustainable or Fair Trade products for interior design practice. Int. J. Sustain. Built Environ. 2015, 4, 100-108. [CrossRef]

8. Pilatowicz, G. Eco-Interiors. A Guide to Environmentally Conscious Interior Design; John Wiley \& Sons, Inc.: New York, NY, USA, 1995; ISBN 0-471-04045-2.

9. Anink, D.; Boonstra, C.; Mak, J. Handbook of Sustainable Building. An Environmental Preference Method for Selection of Materials for Use in Construction and Refurbishment; James \& James (Science Publishers) Ltd.: London, UK, 1998.

10. El Khouli, S.; John, V.; Zeumer, M. Sustainable Construction Techniques. From Structural Design to Interior Fit-Out: Assessing and Improving the Environmental Impact of Buildings; Institut fuer internationale Architektur-Dokumentation GmbH \& Co. KG: München, Germany, 2015.

11. Vale, B.; Vale, R. Green Architecture. Design for a Sustainable Future; Thames and Hudson Ltd.: London, UK, 1996.

12. Kang, M.; Guerin, D.A. The State of Environmentally Sustainable Interior Design Practice. Am. J. Environ. Sci. 2009, 5, 179-186. [CrossRef]

13. Nussbaumer, L.L. Evidence Based Design for Interior Designers; Fairchild Books: New York, NY, USA, 2009.

14. Celadyn, M. The inner space elements in shaping indoor environment quality parameters. In Integration of Art and Technique in Architecture and Urbanism; Wydawnictwa Uczelniane Uniwersytetu Technologiczno-Przyrodniczego: Bydgoszcz, Poland, 2017; Volume 5, pp. 41-50; ISBN 978-83-65603-35-7.

15. Celadyn, M. Inner space elements in environmentally responsible interior design education. World Trans. Eng. Technol. Educ. 2016, 14, 495-499.

16. Reed, B. Integrated design. In Sustainable Commercial Interiors; Bonda, P., Sosnowchik, K., Eds.; John Wiley \& Sons: Hoboken, NJ, USA, 2007; pp. 28-31.

17. Vallero, D.; Brasier, C. Sustainable Design. The Science of Sustainability and Green Design; John Wiley \& Sons Inc.: Hoboken, NJ, USA, 2008.

18. Brand, S. How Buildings Learn. What Happens After They Are Built; Penguin Books: London, UK, 1994.

19. Duffy, F. Design for Change. The Architecture of DEGW; Birkhauser Verlag: Basel, Switzerland; Boston, MA, USA; Berlin, Germany, 1998.

20. Kibert, C.J. Sustainable Construction: Green Building Design and Delivery, 4th ed.; John Wiley \& Sons, Inc.: Hoboken, NJ, USA, 2016; ISBN 978-1-119-05517-4.

21. Schoof, J. Vintage design or conservation of resources? Re-use and recycling in architecture. Detail Green 2015, 1, 6-11.

22. Owen, L.J. A Green Vitruvius. Principles and Practice of Sustainable Architectural Design; James \& James: London, UK, 1999.

23. Keeler, M.; Vaidya, P. Fundamentals of Integrated Design for Sustainable Building, 2nd ed.; John Wiley \& Sons Inc.: Hoboken, NJ, USA, 2016.

24. Szokolay, S.V. Introduction to Architectural Science: The Basis of Sustainable Design; Architectural Press: Oxford, UK, 2010.

25. Schlaffle, E. Aspects of Office Workplace Lighting. In A Design Manual Office Buildings; Hascher, R., Jeska, S., Klauck, B., Eds.; Birkhauser: Basel, Switzerland; Boston, MA, USA; Berlin, Germany, 2002.

26. Yeang, K. Ecodesign. A Manual for Ecological Design; John Wiley \& Sons: London, UK, 2009.

27. Hegger, M.; Fuchs, M.; Stark, T.; Zeumer, M. Energy Manual. Sustainable Architecture; Birkhauser Verlag AG: Basel, Switzerland, 2008. 
28. Celadyn, M. Daylighting in sustainable design of office interiors. Arch. Civ. Eng. Environ. 2016, 9, 1-8.

29. Aronoff, S.; Kaplan, A. Total Workplace Performance. Rethinking the Office Environment; WDL Publications: Ottawa, ON, Canada, 1995.

30. Reed, B. Regenerative Development and Design: Working with the Whole. In Sustainable Construction: Green Building Design and Delivery, 3rd ed.; Kibert, C.J., Ed.; John Wiley \& Sons, Inc.: Hoboken, NJ, USA, 2013; pp. 109-111; ISBN 978-0-470-90445-9. 